\title{
Alopecia types, current and future treatment
}

\begin{abstract}
There are diverse types of alopecia and each call for a specific treatment. Regrettably there is no curative solution to the problem of alopecia as most drugs target its management. The purpose of the review is to explore the different types of alopecia and how each affect hair appearance and growth. The review begins by describing hair structure and hair physiological changes during life progression. A detailed description of conventional medication prescribed for alopecia and associated adverse effects are also pronounced in this review. Both approved (minoxidil and finasteride) and unapproved medications indicated for the condition are discussed to expose voids, which need to be filled by future drug development. The review also discusses the prospective future therapies of alopecia as directed by current research and technological advancement.
\end{abstract}

Keywords: alopecia, hair growth minoxidil, finasteride

Volume 5 Issue 4 - 202 I

\author{
H Rambwawasvika, P Dzomba, L Gwatidzo \\ Department of Chemistry, Bindura University of Science \\ Education, Zimbabwe
}
Correspondence: $\mathrm{H}$ Rambwawasvika, Department of Chemistry, Bindura University of Science Education, P Bag 1020, Bindura, Zimbabwe, Tel +263773934333,

Email rambwawasvika2016@gmail.com

Received: August 12, 2021 | Published: August 26, 202 |

\section{Introduction}

Alopecia is a condition, which results in loss of hair from one's head or other body parts where hair is naturally supposed to be found. The distressful condition causes low self-esteem affecting patients psychologically and socially. ${ }^{1}$ There are diverse categories of alopecia but the commonest are androgenic alopecia (common baldness), alopecia areata and chemotherapy induced alopecia. ${ }^{2}$ Causes of the conditions are many including stress, heredity, hormonal, nutrition, some sickness as well as certain medications like those prescribed for cancer. ${ }^{3-4}$ Although the FDA sanctioned only two serendipitous drugs (finasteride and minoxidil) for the management of alopecia, there are many unapproved medications which are claimed to reverse the condition. ${ }^{5}$ Other products that are claimed to reverse hair loss lack persuading proof from controlled scientific experiments, thereby hindering wider use and commercialization.

Hair grows in a cyclic manner comprising of four phases namely anagen, catagen, telogen and exogen. ${ }^{6}$ These four phases keep on recurring as long as the person's follicles are capable of producing hair. The most active phase of hair growth, commonly known as the anagen last for a period of 2 to 7 years and about $90 \%$ of hair in a healthy scalp are in this phase. ${ }^{7}$ The anagen phase becomes shorter progressively after each cycle causing the production of weaker and villus hair. The phases which follow after the anagen are characterized by hair recession and are shorter in a healthy scalp ${ }^{8}$ (Figure 1).

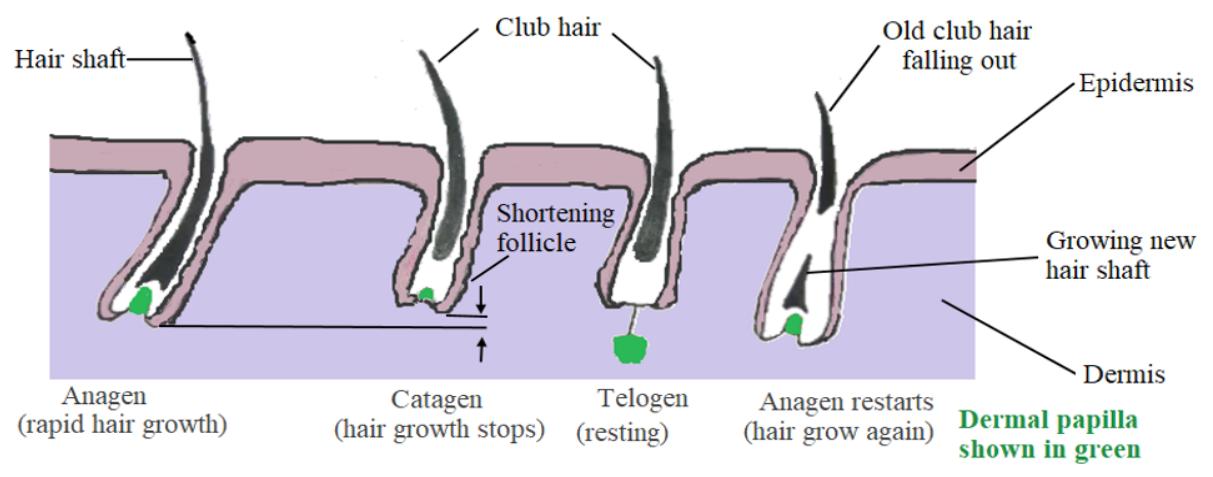

Figure I Changes in hair shaft and dermal papilla during hair cycle.

Generally, all forms of alopecia shorten the hair growth cycle and lead to loss of hair in two ways. The first is the shortening of anagen phase as is characteristic of androgenic alopecia. This results in the drop of anagen: telogen hair ratio from the normal 6:1 to as low as 2:1 and thus lengthening the telogen phase. ${ }^{9}$ The second way is the shrinking of the dermal papilla, which is responsible for hair follicle cell differentiation and growth through the supply of nutrients. The shrinkage of the dermal papilla is due to vasoconstriction of blood vessels supplying nutrients and oxygen to hair. ${ }^{9}$ This leads to hair alteration in both diameter and appearance causing an abrupt change from thick and pigmented hair to vellus distorted hair (thin and white).

\section{Types of alopecia and their causes}

There are many different types of alopecia as there are different causes of the condition. Common types are androgenic alopecia, alopecia areata, chemotherapy induced alopecia (CIA), anagen effluvium, telogen effluvium traction alopecia and trichotillomania. The condition can be classified into two categories; scarring alopecia (instigated by swelling responses to follicle damage) and most common non-scarring alopecia caused by many factors such as hormones, medication, nutrition and certain illnesses. 


\section{Androgenic alopecia}

This is common baldness affecting both male (male pattern baldness) and female (female pattern baldness). It affects mostly men as compared to women because men produce more of the causative male sex hormone testosterone. In women, the condition has a different phenotypical expression depicted as scalp hair thinning unlike the hairline recession in men. ${ }^{10}$ The metabolism of testosterone in the gonads and other parts of the body such as the liver and brain by an enzyme called 5-alpha reductase produces a strong androgen called dihydrotestosterone (DHT). About $10 \%$ of the testosterone produced in the body gets converted to DHT. ${ }^{11}$ DHT, also a sex steroid like testosterone, accelerates baldness more compared to other androgens targeting the same receptor sites with a higher binding affinity(binds easily lasting for 53 minutes were as testosterone lasts for only 35 minutes). The binding of androgensto hair follicle receptors causes progressive shrinkage and weakening of follicles causing destruction of follicle cells. The interface of hair follicle with androgens results in reduced anagen lifespan and prolonged telogen lifespan. According toUrysiak-Czubatka et $\mathrm{al}^{12}$, androgenic alopecia affects $70 \%$ of all men and about $40 \%$ of ladies in their entire lifespan. Male individuals who do not develop baldness generally produce less quantities of the 5-alpha reductase enzyme. Androgenic alopecia affects people of Caucasian origin more than other races. ${ }^{11,13,14}$ Prevalence of this condition across gender and race are depicted on Table 1.

Table I Prevalence of androgenic alopecia across different races ${ }^{11,13,14}$

\begin{tabular}{lll}
\hline Race & Male (\%) & Female (\%) \\
\hline African & 14.5 & 3.5 \\
Caucasian & 79.9 & 45.0 \\
Asian & 60.0 & --- \\
Chinese & 21.4 & 6.0 \\
\hline
\end{tabular}

\section{Alopecia areata}

Alopecia areata is a non-scarring autoimmune condition, which results in loss of hair in one's scalp or any other body parts..$^{15}$ The causative of the condition is still obscure; with some speculations reporting it to be an organ-explicit immune system infection interceded by $\mathrm{T}$ lymphocytes coordinated at hair follicles. ${ }^{16}$ Other reports say hereditary predisposition and natural variables may instigate the sickness. ${ }^{17}$ The condition is characterized by the presence of scattered bald patches around the affected area, usually the scalp. The scalp patches can develop into bigger ones if the condition is not suppressed. The condition affected both male and female equally but most popular in infants. ${ }^{18}$

A deteriorating scenario for alopecia areata is when patients end up with an absolutely hairless scalp (alopecia totalis). Alopecia areata can also result in loss of hair on the whole body, a condition known as alopecia universalis. Alopecia areata may not ordinarily lead to death of hair follicle cells as hair often grows after recovery when proper body signals are assumed. Plenty products have been purported to reverse alopecia areata but none stood the test of time because of ineffectiveness and side effects. Interventions with products such as zinc, cortocosteroids, dithranol, tretinoin, azelaic acid, systematic cortisone, minoxidil and immuno-suppressive remedies have been widely used with limited success to combat alopecia areata. There is still need to find reliable cure for alopecia areata. Other causes of alopecia areata as adopted from Amin and Sachdeva ${ }^{15}$ are summarized on Figure 2.

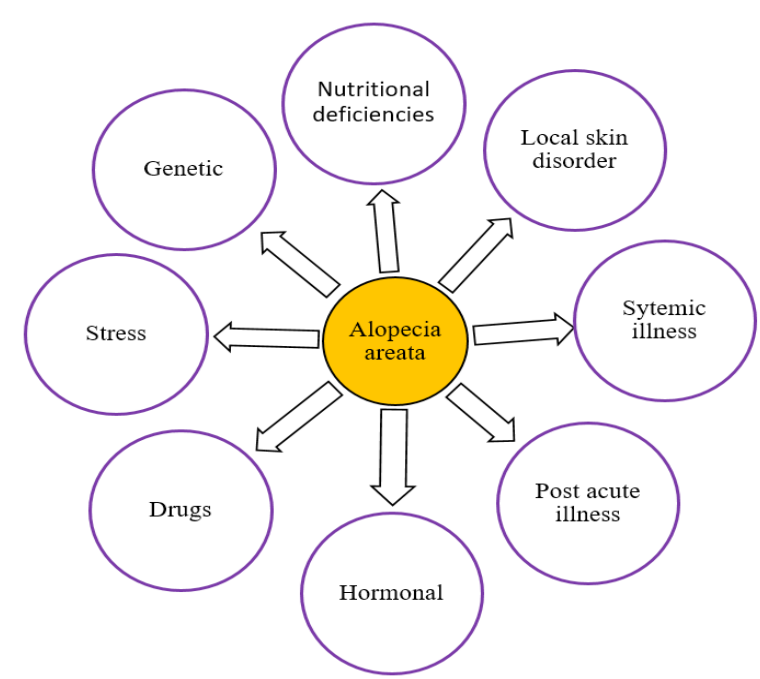

Figure 2 Several causes of Alopecia areata.

\section{Chemotherapy induced alopecia}

Loss of scalp hair is one of the dreaded adverse effects of chemotherapy causing some patients to deny or omit treatment. ${ }^{19}$ Chemotherapy treatments attack fast growing cell types and not only neoplastic cancer cells. This leads to the attack of fast-growing hair fiber keratinocytes in the active growth phase leading to loss of hair. ${ }^{20}$ Hair matrix keratinocytes at the anagen stage are the absolute quickest multiplying cells in the body, about $60 \%$ of them stay in the synthesis (S) stage. Chemotherapeutic medications target rapid growing neoplastic malignancy cells and, in the process, destroying fast growing hair matrix keratinocytes in anagen growth phase. ${ }^{21}$ Consequently, the follicles in the anagen stage are exposed to a faster dystrophic catagen phase followed by the breaking of hair and its subsequent shading.

After chemotherapy, $90 \%$ of hairs in the anagen stage (majority of scalp hair) are transformed to telogen and consequently shade off as club hair but without replacement. This triggers longer telogen phases and shortens anagen phases in the hair cycle. In most cases, hair lost after chemotherapy regrows when the patient stops taking the medication because cycling follicular stem cells are usually not affected by the treatment and will generate a new hair follicle, which will produce a new hair strand later. Decent upkeep of hair follicles during chemotherapy requires therapeutic tactics such as telogen arresting and catagen inhibition. This could be solved by treatment with follicle keratinocytes apoptosis obstructive agents. ${ }^{20}$ Regrettably at present there are no apoptosis obstructive agents or telogen arresting remedies to give to patients. It is desirous to come up with treatments for fortifying hair healthy during chemotherapy.

\section{Anagen effluvium}

The condition results in the shading off of growing hair in the anagen stage (anagen arrest). ${ }^{22}$ Just like chemotherapy induced alopecia the anagen effluvium can be triggered by chemotherapy or other medications. ${ }^{23}$ The condition leads to loss of anagen hair causing very long telogen phase, which lasts for as long the treatment is being administered to the patient. Excessive use of medications like blood thinners, birth control pills, diuretics, and acne drugs is also believed to prompt the disorder. Even though in most cases the condition can be reversed and hair grows back after a period of up to 3 months, the condition can be irreversible leading to psychological torture impacting negatively to the patient's sensitivity of appearance. ${ }^{24}$ 


\section{Telogen effluvium}

Telogen effluvium denotes to non-scarring hair loss due to untimely pushing of hair follicles into the inactive telogen stage. ${ }^{24}$ The disorder is common to the old aged, physical and emotional stressed people, as well as thyroid or other hormonal irregularities. ${ }^{25-26}$ The level of effluvium relies upon the gravity and duration of exposure to the causative agent as opposed to the agent itself. Telogen effluvium can be critical (going on for below six months), chronic (more than six months) or chronic repetitive. ${ }^{26}$

\section{Traction alopecia}

Traction alopecia is typically instigated by tensional straining activities on hair leading to its breakage. ${ }^{27}$ Middle aged ladies are mostly affected because of the high desire to look presentable by trying varying hair styles. Hair styles such as braiding, tight pig tails, repeated chemical treatments like hair bleaching and dying are the basic reasons for traction alopecia. ${ }^{28}$ Traction alopecia happens in people of various cultural origins and is the after effect of a person's hair styling and hair care practices.

\section{Trichotillomania}

This type of alopecia emanates from frequent self-plucking of hair from one's scalp resulting in hair loss or damage. In most cases it is associated with children or psychiatric patients who routinely pluck off their hair. ${ }^{29}$ Interventions in such conditions involve psychiatric treatment for adults and in young children; the habit may disappear as the child grows. ${ }^{30}$

\section{Medication for alopecia}

There are several remedies to manage alopecia albeit plenty reports of adverse reactions and ineffectiveness. Both natural and synthetic remedies are reported although there are only two drugs, (topical minoxidil and oral finasteride) which were sanctioned for hair regrowth by FDA. Due to diversified alopecia types, alopecia drugs are not universally prescribed but rather target a specific type.

\section{Minoxidil (Rogaine)}

Minoxidil, commercial name rogaine is the only FDA sanctioned topical application drug against alopecia. Minoxidil is a pyrimidine derivative originally used as an orally administered treatment for hypertension. ${ }^{31}$ The hair growth promotion popularly known for minoxidil was discovered serendipitously as its side effect for the treatment of hypertension. ${ }^{32}$ Prescriptions for minoxidil are normally packaged in strengths of $5 \%$ (for male use) and $2 \%$ for female use. The drug's mechanism of stimulating hair regrowth remains elusive up to now, although it is a well-known potassium channel opener that is responsible for hyperpolarization of cell membranes. The hyperpolarization causes vasodilation, angiogenesis, and opening of potassium channels thereby facilitating the entrance of more oxygen, blood, and food nutrients to the follicles. ${ }^{33-34}$ Thus, the provision of nutrients and good blood supply is suspected to have some significant contribution to hair rejuvenation by minoxidil. Minoxidil facilitates the transformation of follicles in telogen phase back to anagen. A prolonged active growth phase has also been reported after treatment with topical minoxidil.

\section{Finasteride (Propecia)}

Finasteride (synthetic 4-azasteroid compound) is one of the FDA sanctioned drugs for the treatment of alopecia. Like minoxidil, finasteride was also serendipitously discovered as a hair growth promoter. Prior to its use in trichology, finasteride was used to treat prostate enlargement in men. ${ }^{35}$ Apparently, the drug is prescribed to male patients experiencing hair loss only. Finasteride works by inhibiting 5 alpha reductase, an enzyme that catalyzes the metabolism of testosterone into dihydrotestosterone (DHT). The use of finasteride competitively inhibits the 5 alpha reductase enzymes on the androgen receptors thereby preventing the conversion of testosterone into DHT. Effective results in the handling of androgenic alopecia with finasteride are observed when the drug is administered early or before the death of hair follicles. Unlike minoxidil, which can be used by both male and female patients, finasteride is contraindicated to female patients, particularly pregnant ones due to its teratogenic effect. ${ }^{36}$ Treatment for androgenic alopecia with finasteride often yield reversible hair loss because the drug does not address the genetic cause of the condition and thus hair loss will likely recur. The two approved drugs, minoxidil and finasteride were reported to have side effects in some cases (Table 2).

\section{Unapproved drugs used for alopecia treatment}

Despite there being only minoxidil and finasteride sanctioned by FDA for the treatment of alopecia, there are a plethora of medications purported to manage the condition as shown in Table 3.

Table 2 Summarized side effects of minoxidil and finasteride

\begin{tabular}{|c|c|c|c|}
\hline Topical minoxidil & Oral finasteride & Author & Year \\
\hline Irritation & Low sperm count & $\begin{array}{l}\text { Rossi et al. }{ }^{37} \\
\text { Motofei et al. }{ }^{38}\end{array}$ & $\begin{array}{l}2012 \\
2016\end{array}$ \\
\hline Itching & $\begin{array}{l}\text { Loss of libido } \\
\text { Reduced ejaculation volume }\end{array}$ & $\begin{array}{l}\text { Motofei et al. } .^{38} \\
\text { Kelly et al. }{ }^{13}\end{array}$ & $\begin{array}{l}2016 \\
2016\end{array}$ \\
\hline Contact dermatitis & $\begin{array}{l}\text { Erectile dysfunction } \\
\text { Ejaculation dysfunction }\end{array}$ & $\begin{array}{l}\text { Mulugeta et al. } \\
\text { Kaur et al. }{ }^{36}\end{array}$ & $\begin{array}{l}2019 \\
2013\end{array}$ \\
\hline Facial hair (unwanted hair) & Enlargement (Swelling) of breasts & Bilandi and Kataria ${ }^{32}$ & 2016 \\
\hline $\begin{array}{l}\text { Reversible hair loss upon } \\
\text { stopping medication }\end{array}$ & Menstrual abnormalities & $\begin{array}{l}\text { Usmania and Kataria }{ }^{32} \\
\text { Motofei et al. } .^{38}\end{array}$ & $\begin{array}{l}2016 \\
2016\end{array}$ \\
\hline Burning sensation & $\begin{array}{l}\text { Hair growth on undesignated } \\
\text { places like face }\end{array}$ & Dhariwala and Ravikumar"l & 2019 \\
\hline Dry scalp & A dizzy feeling & $\begin{array}{l}\text { Ateeq Ahmad et al }{ }^{39} \\
\text { Dhariwala and Ravikumar"l }\end{array}$ & $\begin{array}{l}2014 \\
2019\end{array}$ \\
\hline Emergency of rash & Hypersensitivity reactions & $\begin{array}{l}\text { Ateeq Ahmad et al. }{ }^{39} \\
\text { Motofei et al. }{ }^{38}\end{array}$ & $\begin{array}{l}2014 \\
2016\end{array}$ \\
\hline Redness & Testicular pain & $\begin{array}{l}\text { Ateeq Ahmad et al }{ }^{39} \\
\text { (Motofei et al. }^{38}\end{array}$ & $\begin{array}{l}2014 \\
2016\end{array}$ \\
\hline
\end{tabular}


Table 3 Summarized table of unapproved drugs used for the treatment of alopecia

\begin{tabular}{|c|c|c|c|c|}
\hline Drug & Proposed mechanism & Type and condition of alopecia & Author & Year \\
\hline Dutasteride & Inhibition of $5 \alpha$-reductase & Extensive condition & Levy and Emer ${ }^{40}$ & 2013 \\
\hline Photochemotherapy (PUVA) & Immunomodulatory & Patchy surface alopecia areata & Amin and Sachdeva ${ }^{41}$ & 2013 \\
\hline Ketoconazole & Antrogen receptor blocker & Patchy/moderate androgenic alopecia & Fields et al. ${ }^{42}$ & 2020 \\
\hline Diphencyprone (DPCP) & Antigen competition & Extensive alopecia areata & Wiseman et al. ${ }^{43}$ & 2001 \\
\hline Cimetidine & Antiandrogenic & Patchy/moderate androgenic alopecia & Park et al. ${ }^{44}$ & 2018 \\
\hline Oral prednisolone & Multiple mechanisms & Extensive condition alopecia areata & Efentaki et al. ${ }^{45}$ & 2009 \\
\hline Flutamide & Antiandrogen & Patchy alopecia areata & $\begin{array}{l}\text { Lourith and } \\
\text { Kanlayavattanakul }{ }^{46}\end{array}$ & 2013 \\
\hline Sulfasalazine & $\begin{array}{l}\text { immunosuppressive and } \\
\text { immunomodulatory }\end{array}$ & Moderate alopecia areata & Alsantali $^{18}$ & 2011 \\
\hline Dithranol (anthralin) & Immunomodulatory & Extensive alopecia areata & Khan and Chandra ${ }^{47}$ & 2017 \\
\hline Cyclosporine A (CsA) & inhibition of T-cell activation & Moderate alopecia areata & Amin and Sachdeva ${ }^{41}$ & 2013 \\
\hline
\end{tabular}

\section{Herbal remedies for alopecia}

Currently no herbal treatment has been approved for the treatment of alopecia but several studies have shown that some phytochemicals have the propensity to stimulate hair growth on in vitro and in vivo models (Table 4).

\section{Surgical hair transplant}

Hair transplant involves the surgical removal of hair bearing scalp tissue from a donor or other regions of the same scalp to the hairless portion of the body. The practice is mostly done to reverse male pattern baldness compared to other types of alopecia. ${ }^{34,59}$ The temporal and occipital regions of the scalp are not normally affected by androgens and can be a source for hair bearing tissue to be transplanted to bald portions of the same scalp. The two most prevalent surgical procedures are follicular unit strip surgery (FUSS) and follicular unit extraction (FUE). ${ }^{60-61}$ Another challenge of surgical hair transplant is the meticulous care needed for an operation and this calls for experienced medical practitioners who sometimes are hard to come by. Furthermore, there is no assurance that the transferred follicles will stay for a longer duration in the treated person's head before reaching telogen stage. ${ }^{62}$ Other challenges to the patient during hair transplant include excessive bleeding, infection and severe pain. Thus, most people shy away from the process because of these challenges and therefore the need to develop other alternative drugs still stand.

Table 4 Some of the herbs reported to potentiate hair growth

\begin{tabular}{|c|c|c|c|c|}
\hline Name of herb & Proposed mechanism & Active phytochemicals & Author & Year \\
\hline Platycladus orientalis & Hair growth promoter & sesquiterpene & Zhang et $\mathrm{al}^{48}$ & 2018 \\
\hline Glycyrrhiza glabra & Inhibition of $5 \alpha$ reductace & Coumarines, Phytosterols, Flavonoids & Saumendu et a ${ }^{49}$ & 2014 \\
\hline Dicerocaryum senecioides & Hair growth promotion & Flavonoid glycosides & Rambwawasvika et $a^{50}$ & 2019 \\
\hline Cyperusrotundus & Hair growth promotion & Alkaloids, Tannins, glycosides, & Jain et al. ${ }^{25}$ & 2016 \\
\hline Rosmarinus officinalis & Hair growth promoter & I2-methoxycarnosic acid & Murata et al. ${ }^{51}$ & 2013 \\
\hline Urticadioica & Hair growth promoter & flavonoid glycosides & Semalty et al. ${ }^{10}$ & 2011 \\
\hline Ginkgo biloba & Hair growth promoter & Flavonol glycosides, terpene trilactones & Kobayashi et $\mathrm{al}^{52}$ & 1993 \\
\hline Allium cepa (onion) & Hair growth stimulator & Flavonoids & $\left(\right.$ Dorsch $^{53}$ & 1997 \\
\hline Carthamus tinctorius & Follicle cells proliferation & Quinochalcones, Flavonoids & Junlatat and Spripanidkulchai ${ }^{54}$ & 2014 \\
\hline Zizyphus jujube & Hair growth promoter & Essential oils & (Yoon et al. ${ }^{55}$ & 2010 \\
\hline Vitis vinifera (grape) & Proliferation of hair follicles & Polyphenolic, proanthocyanidins & Pietta et al. ${ }^{56}$ & 1998 \\
\hline Lavenda & Hair growth promoter & Essential oils & (Lee et al. ${ }^{57}$ & 2016 \\
\hline Hibiscus rosa-sinensis & Hair growth promoter & Essential oils & Adhirajan et al. ${ }^{58}$ & 2003 \\
\hline
\end{tabular}




\section{Psychological and behavioral therapy}

Like any other social and psychological ills, alopecia patients need counseling to enable them to bear with their conditions. The level of low self-esteem may lead to even fatal cases of suicide as the affected persons fail to accept the condition. ${ }^{63}$ Counseling is crucial especially to adolescence and young ladies who feel like their condition can have negative influence on their sexuality and acceptance in relationships. ${ }^{64}$ In a study done by Lemieux et al. ${ }^{63}$ to investigate the psychological influence of hair loss in cancer patients undergoing chemotherapy, patients with hair loss had stress, low self-esteem and poor body image compared with those without Chemotherapy Induced Alopecia. In a separate study on chemotherapy patients by Rivitti, ${ }^{65}$ cases of psychiatric disorder were more in alopecia patients as compared to a group without alopecia. Thus, psychological support is crucial in the fight against alopecia. Behavioral remedies such as the wearing of wigs, tattoos and hats can also be suggested to patients during counselling. ${ }^{66}$

\section{Nutritional effects in alopecia}

Nutrition has also been found to contribute significantly to hair growth and hair healthy. Apart from the protein needed for hair growth, several nutrients are required in the scalp to facilitate healthy hair growth. Some valuable nutrients and their effect in hair growth are given in Table 5

Table 5 Nutrients important for healthy hair growth ${ }^{44,67,68}$

\begin{tabular}{ll}
\hline Nutrient & Effect on hair growth \\
\hline Zinc & Indicated to patchy surface alopecia \\
Iron & Carries oxygenated blood to the hair follicle cells \\
Selenium & Needed for a healthy scalp \\
Silica & Development of strong hair \\
Copper & Production of antioxidant superoxide dismutase needed for healthy hair \\
Potassium & Moisture and pH maintenance \\
Magnesium & Strengthens hair and facilitate faster growth \\
Calcium & Fast hair growth \\
Vitamin A & Prevents free radicals and inflammation on follicles \\
Vitamin B & Improves shininess and helps grow thick hair \\
Vitamin C & Facilitates faster growth of strong hair and helps absorption of iron \\
Vitamin D & Facilitates hair follicle cycling \\
Vitamin E & Improves circulation of blood and volume reaching the follicles. \\
\hline
\end{tabular}

\section{Prospective future treatment for alopecia}

Technological advancement in drug delivery systems together with the prospect of discovering novel alopecia therapeutics promises better medication for hair loss in future. This is going to be fostered by the high demand of hair growth products and rewarding monetary value offered for alopecia treatment. ${ }^{69}$ Availability of cutting-edge exploration equipment and the existing knowledge base in the field of hair growth is expected to offer concrete groundwork for anti-alopecia prescriptions. ${ }^{70}$ Amongst the promising prospects for future alopecia treatments are: discovery of active hypertrichotic phytochemicals, blended medicines, dermal penetration enhancers, gene therapy and stem cell therapy as shown on Table 6 below.

Table 6 Prospective future treatments for alopecia

\begin{tabular}{|c|c|c|c|}
\hline Prospect treatment & Treatment mechanism & References & Year \\
\hline Blended medicines & Diverse mechanisms depending on treatments mixed & Sheikh et al. ${ }^{72}$ & 2015 \\
\hline Gene therapy & $\begin{array}{l}\text { inserting explicit genes, which will prompt the body to start the } \\
\text { healing, process to patients }\end{array}$ & Meidan and Touitou ${ }^{74}$ & 2001 \\
\hline
\end{tabular}

\section{Conclusion}

In this review, diverse types of alopecia have been discussed with prominence given to their effect on hair follicle andhair growth cycle.
Causes of alopecia such as genetic predisposition, medication, diet, stress, auto immune disorder and prolonged sickness together with their mechanism of reducing hair growth have been discussed. A comprehensive discussion of the existing approved and unapproved 
medication for alopecia together with their pros and cons has been indicated. The review also discussed on the mechanism of action of common drugs used or purported to treat the condition. The last segment of the review was dedicated to giving possible ways by which prospective future therapies must arrest shortcomings of conventional medication using the available knowledge base and technological advancement. Prospect drug discoveries ought to focus not only on developing new alopecia treatments but also refining and adjusting the current drugs to advance hypertrichotic ability as well as reducing adverse effects.

\section{Conflicts of interest}

The authors declare no conflict of interest.

\section{Acknowledgments}

None.

\section{Funding}

None.

\section{References}

1. Upton JH, Hannen RF, Bahta AW, et al. Oxidative stress-associated senescence in dermal papilla cells of men with androgenetic alopecia. Journal of Investigative Dermatology. 2015;135(5):1244-1252.

2. Falto-Aizpurua L, Choudhary S, Tosti A, et al. Emerging treatments in alopecia. Expert opinion on emerging drugs. 2014;19(4):545-556.

3. Hagenaars SP, Hill WD, Harris SE, et al. Genetic prediction of male pattern baldness. PLoS genetics. 2017;13(2):e1006594.

4. Biran R, Zlotogorski A, Ramot Y, et al. The genetics of alopecia areata: new approaches, new findings, new treatments. $J$ dermatol sci. 2015;78(1):11-20.

5. Khidhir KG, Woodward DF, Farjo NP, et al. The prostamide-related glaucoma therapy, bimatoprost, offers a novel approach for treating scalp alopecias. The FASEB Journal. 2013;27(2):557-567.

6. Keum DI, Pi LQ, Hwang ST, et al. Protective effect of Korean Red Ginseng against chemotherapeutic drug-induced premature catagen development assessed with human hair follicle organ culture model. Journal of ginseng research. 2016;40(2):169-175.

7. Mulugeta M, Wang L, Taché Y, et al. Salk Institute for Biological Studies, assignee. Methods for promoting hair growth. United States patent US 10,166,271. 2019.

8. Geyfman M, Plikus MV, Treffeisen E, et al. Resting no more: re-defining telogen, the maintenance stage of the hair growth cycle. Biological Reviews. 2015;90(4):1179-1196.

9. Orasan MS, Roman II, Coneac A, et al. Hair loss and regeneration performed on animal models. Clujul Medical. 2016;89(3):327-334.

10. Semalty M, Semalty A, Joshi GP, et al. Hair growth and rejuvenation: an overview. Journal of Dermatological Treatment. 2011; 22(3):123-132.

11. Dhariwala MY, Ravikumar P. An overview of herbal alternatives in androgenetic alopecia. Journal of cosmetic dermatology. 2019; 18(4):966-975.

12. Urysiak-Czubatka I, Kmieć ML, Broniarczyk-Dyła G et al. Assessment of the usefulness of dihydrotestosterone in the diagnostics of patients with androgenetic alopecia. Postẹpy Dermatologiii Alergologii. 2014;31(4):207-215.

13. Kelly Y, Blanco A, Tosti A et al. Androgenetic alopecia: an update of treatment options. Drugs. 2016;76(14):1349-1364.

14. Kaliyadan F, Nambiar A, Vijayaraghavan S, et al. Androgenetic alopecia: an update. Indian journal of dermatology, venereology and leprology. 2013;79(5):613.
15. Amin SS, Sachdeva S. Alopecia areata: an update. Journal of Pakistan Association of Dermatologists. 2013;23(2):209-220.

16. Broadley D, McElwee KJ. A "hair-raising" history of alopecia areata. Experimental dermatology. 2020;29(3):208-222.

17. Simakou T, Butcher JP, Reid S, et al. Alopecia areata: A multifactorial autoimmune condition. Journal of autoimmunity. 2019;98:74-85.

18. Alsantali A. Alopecia areata: a new treatment plan. Clin, cosmet and investig dermatol. 2011;4:107-115.

19. Ishida K, Ishida J, Kiyoko K, et al. Psychosocial reaction patterns to alopecia in female patients with gynecological cancer undergoing chemotherapy. Asian Pacific Journal of Cancer Prevention. 2015;16(3):1225-1233.

20. Keum DI, Pi LQ, Hwang ST, et al. Protective effect of Korean Red Ginseng against chemotherapeutic drug-induced premature catagen development assessed with human hair follicle organ culture model. Journal of ginseng research. 2016;40(2):169-175.

21. Yeager CE, Olsen EA. Treatment of chemotherapy-induced alopecia. Dermatologic therapy. 2011;24(4):432-442.

22. Kanwar A, Narang T. Anagen effluvium. Indian journal of dermatology, venereology and leprology. 2013;79(5):604.

23. Ghias $\mathrm{MH}$, Amin BD, Kutner AJ et al. Albendazole-induced anagen effluvium. JAAD case reports. 2020;6(1):54-56.

24. Phillips TG, Slomiany WP, Allison R, et al. Hair loss: common causes and treatment. American family physician. 2017;96(6):371-378.

25. Jain PK, Das DE, Das CH et al. Prospect of herbs as hair growth potential. Innovare Journals of Medical Sciences. 2017;5(1):25-33.

26. Fatani MI, Mahdi AH, Alafif KA, et al. Prevalence and factors associated with telogen effluvium in adult females at Makkah region, Saudi Arabia: a retrospective study. Journal of Dermatology \&Dermatologic Surgery. 2015;19(1):27-30.

27. Billero V, Miteva M. Traction alopecia: the root of the problem. Clinical, cosmetic and investigational dermatology. 2018;11:149.

28. Kim HS, Yang MY, Kim GW, et al. Braids or Pony-Tail-Associated Traction Alopecia in Female Children. Annals of Dermatology. 2019; 31(1):117-119.

29. Grant JE, Chamberlain SR. Trichotillomania. American Journal of Psychiatry. 2016;173(9):868-874.

30. Falkenstein MJ, Mouton-Odum S, Mansueto CS, et al. Comprehensive behavioral treatment of trichotillomania: a treatment development study. Behav modif. 2016;40(3):414-438.

31. Rossi A, Mari E, Scarno M, et al. Comparative effectiveness and finasteride vs serenoarepens in male androgenetic alopecia: a two-year study. Int J Immunopathol Pharmacol. 2012;25(4):1167-1173.

32. Bilandi A, Kataria MK. Minoxidil Emulgel for Androgenic Alopecia: A Literature Review Including Patents. International Journal of Pharmaceutics and Drug Analysis. 2016;7:49-58.

33. Maekawa M, Ohnishi T, Balan S, et al. Thiosulfate promotes hair growth in mouse model. Bioscience, biotechnology, and biochemistry. 2019;83(1):114-122.

34. McElwee KJ, Shapiro JS. Promising therapies for treating and/or preventing androgenic alopecia. Skin therapy letter. 2012;17(6):1-4.

35. Lucia MS, Epstein JI, Goodman PJ, et al. Finasteride and high-grade prostate cancer in the Prostate Cancer Prevention Trial. Journal of the National Cancer Institute. 2007;99(18):1375-1383.

36. Kaur H, Kumar S, Kaur G, et al. Alopecia-factors contributing, diagnosis and treatment. International Journal of Pharmaceutical, Chemical \& Biological Sciences. 2013;3(4):1191-1199.

37. Rossi A, Cantisani C, Melis L, et al. Minoxidil use in dermatology, side effects and recent patents. Recent pat inflam allergy drug discovery. 2012; 6(2):130-136. 
38. Motofei IG, Rowland DL, Georgescu SR, et al. Finasteride adverse effects in subjects with androgenic alopecia: A possible therapeutic approach according to the lateralization process of the brain. Journal of Dermatological Treatment. 2016;27(6):495-497.

39. Ateeq Ahmad SS. A new topical formulation of minoxidil and finasteride improves hair growth in men with androgenetic alopecia. J Clin Exp Dermatol Res. 2015;06:6-11.

40. Levy LL, Emer JJ. Female pattern alopecia: current perspectives. Int $\mathrm{j}$ women's health. 2013;5:541-546.

41. Amin SS, Sachdeva S. Alopecia areata: A review. Journal of the Saudi Society of Dermatology \& Dermatologic Surgery. 2013; 17(2):37-45.

42. Fields JR, Vonu PM, Monir RL, et al. Topical ketoconazole for the treatment of androgenetic alopecia: A systematic review. Dermatologic therapy. 2020;33(1):e13202.

43. Wiseman MC, Shapiro J, MacDonald N,et al. Predictive model for immunotherapy of alopecia areata with diphencyprone. Archives of dermatology. 2001;137(8):1063-1068.

44. Park AM, Khan S, Rawnsley J, et al. Hair biology: growth and pigmentation. Facial Plastic Surgery Clinics. 2018;26(4):415-424.

45. Efentaki P, Altenburg A, Haerting J, et al. Medium-dose prednisolone pulse therapy in alopecia areata. Dermato-endocrinol. 2009;1(6):311314.

46. Lourith N, Kanlayavattanakul M. Hair loss and herbs for treatment Journal of cosmetic dermatology. 2013;12(3):210-222.

47. Khan MA, Chandra S. Advance approaches in alopecia. Pharmaceutical and Biological Evaluations. 2017;4:135-140.

48. Zhang Y, Han L, Chen SS, et al. Hair growth promoting activity of cedrol isolated from the leaves of Platycladusorientalis. Biomed Pharmacotherapy. 2016;83:641-647.

49. Saumendu DR, Raj KP, Suvakanta D, et al. Hair growth stimulating effect and phytochemical evaluation of hydro-alcoholic extract of Glycyrrhiza glabra. Global Journal of Research on Medicinal Plants \& Indigenous Medicine. 2014;3(2):40.

50. Rambwawasvika H, Dzomba P, Gwatidzo L, et al. Hair Growth Promoting Effect of Dicerocaryum senecioides Phytochemicals. International journal of medicinal chemistry. 2019;1-10.

51. Murata K, Noguchi K, Kondo M, et al. Promotion of hair growth by Rosmarinus officinalis leaf extract. Phytotherapy research. 2013; 27(2):212-217

52. Kobayashi N, Suzuki R, Koide C, et al. Effect of leaves of Ginkgo biloba on hair regrowth in $\mathrm{C} 3 \mathrm{H}$ strain mice. Yakugakuzasshi: Journal of the Pharmaceutical Society of Japan. 1993;113(10):718-724.

53. Dorsch W. Allium cepa L (Onion): Part 2 chemistry, analysis and pharmacology. Phytomedicine. 1997;3(4):391-397.

54. Junlatat J, Sripanidkulchai B. Hair Growth Promoting Effect of Carthamus tinctorius Floret Extract. Phytotherapy research. 2014; 28(7):1030-1036.

55. Yoon JI, Al-Reza SM, Kang SC, et al. Hair growth promoting effect of Zizyphusjujuba essential oil. Food and chemical toxicology. 2010;48(5):1350-1354.

56. Pietta P, Simonetti P, Mauri P, et al. Antioxidant activity of selected medicinal plants. Journal of Agricultural and Food Chemistry. 1998;46(11):4487-4490.
57. Lee BH, Lee JS, Kim YC. Hair growth-promoting effects of lavender oil in C57BL/6 mice. Toxicological research. 2016; 32(2):103-108.

58. Adhirajan N, Kumar TR, Shanmugasundaram $\mathrm{N}$, et al. In vivo and in vitro evaluation of hair growth potential of Hibiscus rosa-sinensis Linn. Journal of ethnopharmacology. 2003;88(2-3):235-239.

59. Olsen EA, Messenger AG, Shapiro J, et al. Evaluation and treatment of male and female pattern hair loss. Journal of the American Academy of Dermatology. 2005;52(2):301-311.

60. Navarro RM, Pino A, Martinez Andres A, et al. The effect of plasma rich in growth factors combined with follicular unit extraction surgery for the treatment of hair loss: a pilot study. Journal of cosmetic dermatology. 2018;17(5):862-873.

61. Leavitt M, David PM, Rao NA, et al. Effects of finasteride (1 mg) on hair transplant. Dermatologic surgery. 2005;31(10):1268-1276.

62. Perez-Meza D, Niedbalski R. Complications in hair restoration surgery. Oral and maxillofacial surgery clinics of North America. 2009; 21(1):119-148.

63. Lemieux J, Maunsell E, Provencher L, et al. Chemotherapy-induced alopecia and effects on quality of life among women with breast cancer: a literature review. Psycho-Oncology: Journal of the Psychological, Social and Behavioral Dimensions of Cancer. 2008;17(4):317-328.

64. Li SJ, Huang KP, Joyce C, et al. The impact of alopecia areata on sexual quality of life. International journal of trichology. 2018; 10(6):271-274.

65. Rivitti EA. Alopecia areata: revisão e atualização. Anais Brasileiros de Dermatologia. 2005;80(1):57-68.

66. Strazzulla LC, Wang EH, Avila L, et al. Alopecia areata: an appraisal of new treatment approaches and overview of current therapies. $J$ Am Acad Dermatol. 2018;78(1):15-24.

67. Betsy A, Binitha MP, Sarita S, et al. Zinc deficiency associated with hypothyroidism: an overlooked cause of severe alopecia. Int $j$ trichology. 2013;5(1):40-42.

68. Damodaran RG, Gupta R. Hair loss and the applied techniques for identification of novel hair growth promoters for hair re-growth. Pharmacognosy Journal. 2011;3(22):1-5.

69. Wipf A, Boysen N, Hordinsky MK, et al. The rise of transcutaneous drug delivery for the management of alopecia: a review of existing literature and an eye towards the future. Journal of Cosmetic and Laser Therapy. 2019;21(5):247-254.

70. Strazzulla LC, Wang EH, Avila L, et al. Alopecia areata: an appraisal of new treatment approaches and overview of current therapies. Journal of the American Academy of Dermatology. 2018;78(1):15-24.

71. Li Y, Yan B, Wang H, et al. Hair regrowth in alopecia areata patients following Stem Cell Educator therapy. BMC medicine. 2015; 13(1):1-1.

72. Sheikh S, Ateeq A, Shoukath MA, et al. A new topical formulation of minoxidil and finasteride improves hair growth in men with androgenetic alopecia. Journal of Clinical \& Experimental Dermatology Research. 2015;6(1):253.

73. Ramkanth S, Chetty CM, Sudhakar Y, et al. Development, characterization \&invivo evaluation of proniosomal based transdermal delivery system of Atenolol. Future Journal of Pharmaceutical Sciences. 2018;4(1):80-87.

74. Meidan VM, Touitou E. Treatments for androgenetic alopecia and alopecia areata. Drugs. 2001;61(1):53-69. 